\title{
CHARACTERIZATION, ACTIVATION ENERGY \& THERMODYNAMIC PARAMETER OF CRYSTALS SYNTHESIZED FROM SOLVENT
} EVAPORATION METHOD

\author{
K. R. Patel ${ }^{1}$, Dhara Patel ${ }^{1}$ and V D Patel ${ }^{2}$ \\ 1 M.L. Institute of diploma studies Bhandu, \\ 2 Municipal Arts \& Urban Science College, \\ Mehsana kirti3183@gmail.com
}

\begin{abstract}
Crystal from transition metal $\mathrm{Co}(\mathrm{II}), \mathrm{Cu}(\mathrm{II})$ and $\mathrm{Ni}(\mathrm{II})$ with Schiff base have been synthesized . They were characterized by Elemental analysis, Infrared spectra, Electronic spectra and Thermo gravimetric analysis. Kinetic Parameters, such as energy of activation (Ea), enthalpy $(\Delta \mathrm{H \# )}$, entropy $(\Delta \mathrm{S} \#)$ and Gibbs energy $(\Delta \mathrm{G} \#)$, were computed from the TGA data. Based on the thermal studies, Thermal stability and kinetic parameters of these complexes were studied by employing Thermo gravimetric Analysis (TGA). The TGA graph shows that the complexes are stable up to $300{ }^{\circ} \mathrm{C}$ temperature. Decomposition takes place in four stages. Activation energy for decomposition has been calculated using Broido method. Mathematical analysis of the data has allowed us to determine various parameters using integral method using the coats-Redfern equation and the approximation method using the Horowitz-Metzger equation. The trend of the kinetic parameters was found to be different from that of the thermal stability order.
\end{abstract}

\section{Keywords:}

Synthesis, Thermal degradation, Enthalpy, Entropy, Gibbs Parameter, Activation parameters

\section{Introduction}

The crystals of Schiff bases derived from heterocyclic compounds have been the centre of attraction for many workers in recent years.[1-3]. The physicochemical data suggested tetrahedral geometry for the $\mathrm{Cu}(\mathrm{II}), \mathrm{Co}(\mathrm{II})$ and $\mathrm{Ni}(\mathrm{II})$ crystals. Thermo kinetic and spectral studies of metal complexes some Schiff bases [4] TGA is commonly employed in research and testing to determine characteristics of materials such as polymers, In presence study The thermal behavior (TGA) of the crystals was studied and kinetic parameters were determined by Broido method [5]. Very few systems have been reported [6] 
showing the relationship between thermal stability of crystals and structure of the chelating agents. Wendlandt and co-workers[7-9] and Hill and coworkers[10] studied the thermal properties of crystals with different types of complexing ligands. Structural studies on several metal chelates of 1-diketones and 2-hydroxycarbonyl compounds have been reviewed by Holm and O'

Connor. The Broido method was used to evaluate the kinetic parameters from the TGA curves. Plots of $\ln (\ln 1 / \mathrm{y})$ versus $1000 / \mathrm{T}$ (where $\mathrm{y}$ is the fraction not yet decomposed) for different stage of the thermal degradation of the crystals and evaluation of kinetic parameters the integral method using the CoatsRedfern equation and the approximation method using the Horowitz- Metzger equation.

\section{Experimental}

Synthesis of $\mathrm{Co}(\mathrm{II}), \mathrm{Cu}(\mathrm{II})$ and $\mathrm{Ni}(\mathrm{II})$ crystals

The crystals were prepared by mixing Schiff base $(0.1 \mathrm{~mol})$ in hot ethanol solution to $(0.1 \mathrm{~mol})$ metal chloride salt solution prepared in distilled water. The schiff base solution was added slowly with continuous stirring to metal solution. It was refluxed for 3 hours and after refluxation, the mixture was heated for 10 minutes till the contents was reduced to half. Then the crystals precipitated out after being cooled. The precipitate was filtered and washed with the distilled water. All crystals were dried and kept in vacuum desiccators.

Elemental analyses were performed with a Perkin-Elmer 2400 series -II, C-H$\mathrm{O}-\mathrm{N}-\mathrm{S}$ analyzer. The metal content was determined [11] by titration with a solution of standardized disodium salt of EDTA after. The conductivity of crystals was measured in DMF as solvent using conductivity meter model, Systronic $361 \mu$ digital. All the crystals showed the molar conductance values for $10^{-3} \mathrm{M}$ concentration in range 2 to $78 \mathrm{ohm}^{-1} \mathrm{~cm}^{2} \mathrm{~mol}^{-1}$. The IR spectra were recorded in the range $4000-400 \mathrm{~cm}^{-1}$ on a Perkin-Elmer-783 instrument in $\mathrm{KBr}$ pellets. Thermo gravimetric analysis of the crystals was carried out in air by 
heating at a constant rate of $10^{\circ} \mathrm{C}$ per minute using a Perkin-Elmer TGA-7DSCPYRIS-1-DTA-7 thermal analysis system. The activation energy (Ea) of the degradation process were obtained by the Broido method

\section{Results And Discussion}

All the synthesized crystals in DMF. The analytical data (not shown) were reveals a stoichiometry of 1:2, metal: ligand. The molar conductance values of $10^{-3} \mathrm{M}$ solutions in DMF were in the range of $8.58-16.22 \mathrm{ohm}^{-1} \mathrm{~cm}^{2} \mathrm{~mol}^{-1}$, indicating a non-electrolytic behavior of the complexes. IR and Electronic spectral data were obtained(not shown).

\section{Thermal studies}

The cumulative weight loses of metal crystals at $50 \mathrm{C}, 100^{\circ} \mathrm{C}, 150^{\circ} \mathrm{C}, 200^{\circ} \mathrm{C}$ and $250^{\circ} \mathrm{C}$ are presented in [Table 1] Decomposition of all crystals starts above $350^{\circ} \mathrm{C}$. The rate of decomposition of crystals is lower than that of the ligand suggested that there may be weak intermolecular hydrogen bonding. Co(II) thermograms also shows the presence of six water molecules and loss in weight equivalent to $15-20 \%$ at $100^{\circ} \mathrm{C}$ to $150^{\circ} \mathrm{C}$. Again presence of water molecules is observed in $\mathrm{Cu}(\mathrm{II})$ crystals. These crystals show loss 5 to $8 \%$ equivalent to two water molecules at $100^{\circ} \mathrm{C}$ to $150^{\circ} \mathrm{C}$. The final product is found to be metal oxide in all the crystals. Thermo gravimetric analysis shows that all synthesized crystals are hydrated and have water molecules associated to them. Co(II) has six, $\mathrm{Ni}(\mathrm{II})$ has four and $\mathrm{Cu}(\mathrm{II})$ has two water molecules as part of their structure. All crystals lost hydration water $50^{\circ} \mathrm{C}$ and $150^{\circ} \mathrm{C}$ and then the coordinated water molecule was lost above $\geq 250^{\circ} \mathrm{C}$.The decomposition was complete at $>600^{\circ} \mathrm{C}$ for all crystals. The TGA curves of all crystals were shown in [Figure 1].

Activation Energy and Thermodynamic Parameters studies 
The Broido method was used to evaluate the kinetic parameters from the TGAcurves. Plots of $\ln (\ln 1 / \mathrm{y})$ versus $1000 / \mathrm{T}$ (where $\mathrm{y}$ is the fraction not yet decomposed) for four stage of the thermal degradation of the crystals are shown in [Figure2]. The slope of the plot $\ln (\ln 1 / \mathrm{y})$ versus $1000 / \mathrm{T}$ is related to the energy of activation as

$\mathrm{Ea}=-2.303 \times \mathrm{R} \times$ slope $(1)$

Where, $\mathrm{R}=$ gas constant.

The parameters, enthalpy $(\Delta \mathrm{H} \#)$, entropy $(\Delta \mathrm{S} \#)$ and Gibbs energy $(\Delta \mathrm{G} \#)$ of activation were calculated using the following standard equations

$\Delta \mathrm{H} \#=\mathrm{Ea}-\mathrm{R} \mathrm{Td}$

$\Delta \mathrm{S} \#=\Delta \mathrm{H} \# / \mathrm{T}-4.576 \log \mathrm{T} / \mathrm{K}^{،}-47.22$

where $\mathrm{K}^{\star}=-\ln (\ln 1 / \mathrm{y})$

$\Delta \mathrm{G} \#=\Delta \mathrm{H} \#-\Delta \mathrm{TS} \#$

The activation energies of decomposition were the range (15.41-98.57), (15.9337.55), and (17.34-67.65) $\mathrm{kJ} \mathrm{mol}^{-1}$ in $\mathrm{Cu}(\mathrm{II}), \mathrm{Co}(\mathrm{II})$ and $\mathrm{Ni}(\mathrm{II})$ respectively. The high values of the activation energies reflect the thermal stability of the crystals [12-13]. The entropy of activation $(\Delta \mathrm{S} \#)$ and enthalpies of activation $(\Delta \mathrm{H} \#)$ values for four steps of all the crystals are negative and the negative values of the entropies of activation are compensated by the values of the enthalpies of activation leading to almost the same values (27827-28731 $\mathrm{kJ} \mathrm{mol}^{-1}$ ) for the free energies of activation $(\Delta \mathrm{G} \#)$. The data were summarized in [Table 2]. The entropy of activation had negative values in all the complexes, which indicates that the decomposition reactions proceed with a lower rate than normal ones.

\section{Kinetic calculations}

The kinetic and thermodynamic parameters viz. the order of the reaction (n), the energy of activation $(\mathrm{Ea})$, the pre-exponential factor $(Z)$, the entropy of activation $(\Delta \mathrm{S} \#)$ and the Gibbs energy change $(\Delta \mathrm{G} \#)$, together with the correlation coefficient $(r)$ for the non-isothermal decomposition of the crystals, 
were determined by the Horowitz-Metzer (HM) approximation method[14] and the Coats-Redfern integral method. The obtained data are given in [Table 3]. The results showed that the values obtained by two methods are comparable. The calculated values of the activation energy of the crystals are relatively low, indicating the autocatalytic effect of the metal ion on the thermal decomposition of the crystal. The negative activation entropy value indicates that the activated crystals were more ordered than the reactant and that the reactions were slow. The more ordered nature may be due to the polarization of bonds in the activated state, which might occur through charge transfer electronic transitions.

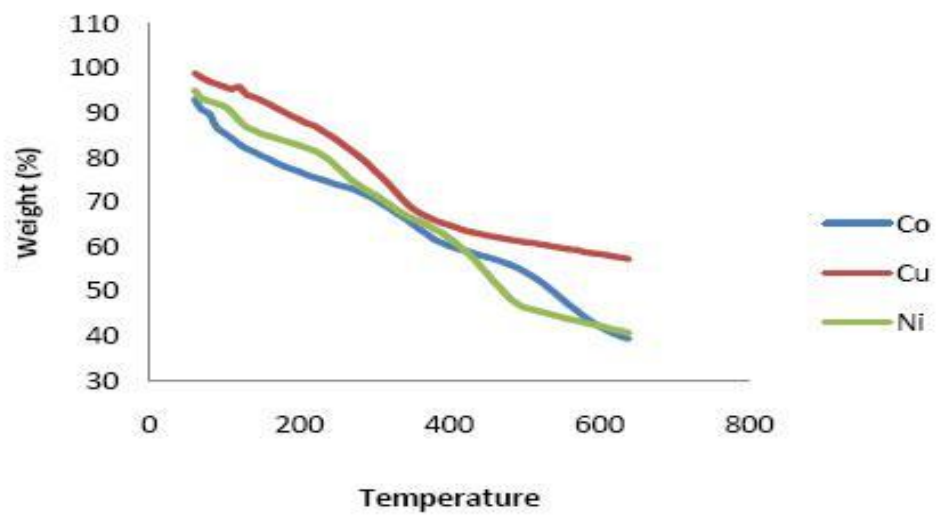

Figure 1: TGA curves for crystals



Fig 2: Plot of $\ln [\ln (1 / y)]$ vs $1000 / T$ for crystals 
Table - 1 Thermogravitomatric Analyses of Crystals

\begin{tabular}{|c|c|c|c|c|c|c|c|c|c|c|}
\hline \multirow{3}{*}{ Crystal } & \multicolumn{10}{|c|}{ Found } \\
\hline & \multicolumn{2}{|l|}{$50^{\circ} \mathrm{C}$} & \multicolumn{2}{|l|}{$100^{\circ} \mathrm{C}$} & \multicolumn{2}{|l|}{$150^{\circ} \mathrm{C}$} & \multicolumn{2}{|l|}{$200^{\circ} \mathrm{C}$} & \multicolumn{2}{|l|}{$250^{\circ} \mathrm{C}$} \\
\hline & $\mathrm{G}$ & $\%$ & $\bar{G}$ & $\%$ & $\bar{G}$ & $\%$ & $\mathrm{G}$ & $\%$ & $\overline{\mathrm{G}}$ & $\%$ \\
\hline$\left[\mathrm{Co} \cdot \mathrm{L}_{2}\right] \cdot 6 \mathrm{H}_{2} \mathrm{O} \cdot \mathrm{Cl}_{2}$ & 7.14 & 1 & 107.23 & 15 & 142.98 & 20 & 150 & 24 & 193.00 & 27 \\
\hline$[\mathrm{Ni} \cdot \mathrm{L} 2] .4 \mathrm{H} 2 \mathrm{O} . \mathrm{Cl} 2$ & 0.678 & 0.1 & 61.08 & 9 & 101.80 & 15 & 122.16 & 18 & 156.1 & 23 \\
\hline$[\mathrm{Cu} \cdot \mathrm{L} 2] \cdot 2 \mathrm{H} 2 \mathrm{O} \cdot \mathrm{Cl} 2$ & 0.64 & 0.1 & 32.37 & 5 & 51.80 & 8 & 77.70 & 12 & 116.55 & 18 \\
\hline
\end{tabular}

Table -2 Activation energy and Thermodynamic parameters Crystals

\begin{tabular}{|c|c|c|c|c|c|c|}
\hline Crystals & stage & Temp range ${ }^{0} \mathrm{C}$ & $\mathrm{Ea} \mathrm{kJ} \mathrm{mol}^{-1}$ & $(\mathrm{H \# )}$ & (S\#) & (G\#) \\
\hline \multirow{4}{*}{.$[\mathrm{Co} \cdot \mathrm{L} 2] 6 \mathrm{H} 2 \mathrm{O} \mathrm{Cl} 2$} & $\mathrm{i}$ & $60-90$ & 67.65324 & -6608.49 & -42.0776 & 27887.45 \\
\hline & ii & $90-270$ & 17.34607 & -6658.8 & -42.1534 & 27937.68 \\
\hline & $\mathrm{iii}$ & $270-500$ & 25.53418 & -6650.61 & -42.1411 & 27929.51 \\
\hline & iv & $500-620$ & 55.66773 & -6620.47 & -42.0956 & 27899.42 \\
\hline \multirow{4}{*}[\mathrm{Ni}\cdot\mathrm{L}2]{$\cdot 4 \mathrm{H} 2 \mathrm{O} \mathrm{Cl} 2$} & $\mathrm{i}$ & $60-130$ & 30.86655 & -6645.28 & -42.0595 & 28716.94 \\
\hline & ii & $130-220$ & 15.93904 & -6660.2 & -42.0814 & 28731.84 \\
\hline & iii & $220-490$ & 37.55796 & -6638.58 & -42.0497 & 28710.25 \\
\hline & iv & $490-640$ & 20.33129 & -6655.81 & -42.075 & 28727.46 \\
\hline \multirow{4}{*}[\mathrm{Cu}\cdot\mathrm{L}2]{$\cdot 2 \mathrm{H} 2 \mathrm{O} \cdot \mathrm{Cl} 2$} & $\mathrm{i}$ & $60-100$ & 48.44321 & -5879.44 & -41.4362 & 27877.8 \\
\hline & ii & $100-130$ & 98.57009 & -5829.31 & -41.3617 & 27827.75 \\
\hline & $\mathrm{iii}$ & $130-370$ & 40.5706 & -5887.31 & -41.4479 & 27885.66 \\
\hline & iv & $370-640$ & 15.41761 & -5912.46 & -41.4852 & 27910.78 \\
\hline
\end{tabular}

Table -3 Kinetic parameter of degradation of the crystals calculated by the HorowitzMetzger and Coats-Redfern methods 


\begin{tabular}{|c|c|c|c|c|c|c|c|c|}
\hline Crystals & stage & $\mathbf{n}$ & Method & $\begin{array}{l}\mathbf{E a} \\
\mathbf{k J} \mathbf{~ m o l}^{-1} \\
\end{array}$ & \begin{tabular}{|l|}
$Z$ \\
$s-1$ \\
\end{tabular} & $\begin{array}{c}\text { S\# } \\
\text { J K-1 } \text { mol}^{-1} \\
\end{array}$ & \begin{tabular}{|c|}
$\mathrm{G} \#$ \\
$\mathbf{k J} \mathbf{~ m o l}^{-1}$ \\
\end{tabular} & $\mathbf{r}$ \\
\hline \multirow{4}{*}{ [Co·L2] 6H2O Cl2 } & I & \multirow{2}{*}{1.10} & \multirow{2}{*}{$\begin{array}{l}\text { Horowitz- } \\
\text { Metzger equation }\end{array}$} & 25.5320 & 0.7060 & -47.2231 & 31299.00 & 0.95 \\
\hline & II & & & 25.5012 & 0.9091 & -46.3342 & 30709.66 & 0.95 \\
\hline & I & \multirow{2}{*}{0.90} & \multirow{2}{*}{$\begin{array}{l}\text { Coats- } \\
\text { equation }\end{array}$} & 58.7502 & 5.202 & -43.0250 & 28515.66 & 0.95 \\
\hline & II & & & 58.7451 & 5.313 & -43.2201 & 28645.01 & 0.95 \\
\hline \multirow{4}{*}[\mathrm{Ni}\cdot\mathrm{L}2]{$\cdot 4 \mathrm{H} 2 \mathrm{O} \mathrm{Cl} 2$} & I & \multirow{2}{*}{0.80} & \multirow{2}{*}{$\begin{array}{l}\text { Horowitz- } \\
\text { Metzger equation }\end{array}$} & 35.8632 & $9.41 \times 10^{11}$ & -48.0212 & 31828.14 & 0.96 \\
\hline & II & & & 33.5574 & $3.5 \times 10^{9}$ & -48.335 & 32036.19 & 0.96 \\
\hline & I & \multirow{2}{*}{1.05} & \multirow{2}{*}{$\begin{array}{l}\text { Coats- } \\
\text { equation } \\
\end{array}$} & 19.2023 & 60.3 & -55.809 & 37011.30 & 0.95 \\
\hline & II & & & 16.2455 & 49.11 & -55.707 & 36943.50 & 0.95 \\
\hline \multirow{4}{*}[\mathrm{Cu}\cdot\mathrm{L}2]{$\cdot 2 \mathrm{H} 2 \mathrm{O} \cdot \mathrm{Cl} 2$} & I & \multirow{2}{*}{1.00} & \multirow{2}{*}{$\begin{array}{l}\text { Horowitz- } \\
\text { Metzger equation }\end{array}$} & 101.2587 & $1.5 \times 10^{27}$ & -41.2281 & 27324.31 & 0.96 \\
\hline & II & & & 99.5684 & $1.6 \times 10^{23}$ & -40.2323 & 26664.10 & 0.96 \\
\hline & $\mathrm{I}$ & \multirow{2}{*}{1.42} & \multirow{2}{*}{$\begin{array}{ll}\begin{array}{l}\text { Coats- } \\
\text { equation }\end{array} & \text { Redfern } \\
\end{array}$} & 41.7862 & $1.9 \times 10^{6}$ & -40.2051 & 26646.06 & 0.95 \\
\hline & II & & & 40.5834 & $5.4 \times 10^{5}$ & -40.1520 & 26610.86 & 0.95 \\
\hline
\end{tabular}

\section{References}

Thankamony, M., Mohanan, K. (2007). Synthesis, spectral studies, thermal decomposition kinetics, reactivity and antibacterial activity of some lanthanide(III nitrate complexes of 2-(N-indole-2-one)amino-3carboxyethyl-4,5,6,7- tetrahydrobenzo- [b]thiopheneIndian. J. Chem., 46A, 247.

Raman, N., Dhaveethu Raju, J., Sakthivel, A.( 2007). Synthesis, spectral characterization of Schiff base transition metal complexes: DNA cleavage and antimicrobial activity studies. J. Chem. Sci., 119, 303.

Wang, D., Yang, Y., Zhao, T., Wu, X., Wang, S., Hou, Y., Chen, W. (2006), Synthesis and properties of a Pr(III) complex with 2acetylbenzimidazoledehyde-glycine Schiff-base ligand. Chin. Sci. Bull., 51,785 .

Sanjiv, A., Sohan, L., Satish, K., Mahender, K., Comparative degradation kinetic studies of three biopolymers: Chitin, chitosan and cellulose.

Archives of Applied Science Research, 3(2011), 3, pp. 188-201.

Broido, A. (1761). A simple, sensitive graphical method of treating thermogravimetric analysis data. J. Poly. Sci., 7A(2), 1761. 
Wendlandt, W. W. (1957). The thermal decomposition of the 5,7-dihalo-8quinolinol rare earth metal chelates. Anal. Chim. Acta, 17, 428.

Ascenzo, G D., Wendlandt, W. W. (1970). The thermal properties of some metal pyridinecarboxylates. Anal. Chim. Acta, 50, 79.

Chang, F. C., Wendlandt, W. W. (1971). Thermal reactions of coordination compounds: Part II. Chlorobromobis(ethylenediamine)- and dibromobis(ethylenediamine)- cobalt (III) complexes. Thermochim Acta, 2(4) , 293.

Perry, D. L., Vaz, C. Wendlandt, W. W. (1974). The thermogravimetry and differential thermal analysis curves of some di-2- pyridyl ketone nickel(II) complexes. Thermochim Acta, 9, 76.

Scency, C. G., Hill, J. O., Magee, R., J. (1975). Thermal analysis of copper dithiocarbamates. Thermochim Acta, 11, 301.

Vogel, A.I. (1962). A Text Book of Quantitative Analysis, 5th ed., Longmans Green, London.

Moamen, S. R., Ibrahim, M., Hassan, K. (2006). Synthesis and spectroscopic studies of some transition metal complexes of a novel Schiff base ligands derived from 5-phenylazo-salicyladehyde and o-amino benzoic acid. Spectrochemica Acta PartA, 65(5), 1208-1220

Kamellia, N., Zolfaghar, R., Masoud, S. (2009). The synthesis, characterization, thermal and optical properties of copper, nickel, and vanadyl complexes derived from azo dyes. Dyes and Pigments 83, 304311.

Horowitz, H. H., Metzger, G. (1963). A New Analysis of Thermogravimetric Traces. Anal. Chem., 35, 1464. 